\title{
Полногеномное секвенирование культурных и дикорастущих форм винограда (Vitis vinifera L.)
}

\author{
Е.А. Григорьева 凶, М.М. Агаханов, И.В. Александрова, В.А. Волков \\ Федеральный исследовательский центр Всероссийский институт генетических ресурсов растений им. Н.И. Вавилова (ВИР), 190000, г. Санкт-Петербург,
} ул. Большая Морская, д. 42, 44

() Авторы, 2019

هe.grigoreva@vir.nw.ru
Аннотация. Виноград является наиболее широко культивируемой и экономически важной плодовой культурой в мире. Развитие виноградарства предполагает создание коммерчески успешных сортов, устойчивых к фитопатогенам, способных плодоносить и вызревать в различных климатических условиях. Селекция винограда становится эффективнее с пониманием процессов доместикации, которое невозможно без наличия информации о геномной структуре вида. Эта информация открывает возможности применения методов геномной селекции, а также методов маркер-опосредованной селекции для поиска потенциально важных аллелей генов. Помимо этого становится возможным изучение некоторых эволюционных процессов винограда, таких как переход к обоеполому типу цветка в процессе доместикации. Статья рассматривает вопрос о состоянии исследований в области полногеномного секвенирования культурных форм и дикорастущих предков культурного винограда, приведена информация о текущем статусе геномных сборок и их статистических показателях.

Ключевые слова: виноград; полногеномное секвенирование; высокопроизводительное секвенирование; геномная сборка.

Благодарности. Исследования выполнены в рамках темы НИР № 0662-2019-0004 госзадания ВИР.

\section{Whole genome sequencing of cultivated and wild varieties of grapevine (Vitis vinifera L.)}

\author{
E.A. Grigoreva@, M.M. Agakhanov, I.V. Alexandrova, V.A. Volkov \\ Vavilov All-Russian Institute of Plant Genetic Resources (VIR), St. Petersburg, 190000, Russia
}

Autors, 2019

هe.grigoreva@vir.nw.ru

\begin{abstract}
The Eurasian grapevine is one of the most widely cultivated and economically important fruit crop in the world. The development of commercially successful grapevine varieties is hampered by a lack of information about the structure of its genomes. In particular, this information is important for breeding of pathogen-resistance varieties that would be able to develop bunches under different climate conditions. The breeding of grapevine becomes more effective with an understanding of domestication processes which is impossible without knowledge of grapevine genome structure. This information provides an opportunity of applying methods of genomic and marker-assisted selection aimed at finding new important alleles. Besides, it becomes possible to study evolution processes of grapevine such us the changing of a flower type during domestication. This paper contains information about the current state of whole genome sequencing of cultivated grape and its wild progenitors.
\end{abstract}

Key words: grapevine; whole genome sequencing; NGS; genome assembly.

\section{Виноград как культура}

Вид Vitis vinifera L. включает в себя два подвида: виноград культурный V. vinifera L. ssp. sativa (DC.) Неgi и виноград дикорастущий V. vinifera ssp. sylvestris (Gmelin) Hegi. Многие авторы, опираясь на работы ботаника К.К. Гмелина (С. C. Gmelin), считают, что культурный виноград произошел от дикорастущего предка V. vinifera ssp. sylvestris, который в настоящее время считается практически ис- чезнувшим во многих местах первоначального ареала, что с каждым годом усложняет условия для его поиска (Ocete et al., 2008; Arnold et al., 2010). Основным фенотипическим признаком «диких виноградных лоз», отличающим дикий виноград от культурного, является двудомность (Негруль, 1968; Волынкин и др., 2009). Особи дикого винограда имеют или только мужские цветки с длинными прямыми тычинками и редуцированным пестиком, или 
функционально женские цветки с хорошо развитым пестиком и короткими, отогнутыми вниз тычинками со стерильной пыльцой. Культурные сорта винограда в основном характеризуются гермафродитным типом цветка, и только сравнительно немногие из них имеют функционально женский цветок. Также стоит отметить, что ни при гибридизации, ни в результате инцухта появления особей с мужскими цветками не наблюдается (Бузин и др., 1937).

В процессе доместикации дикие формы винограда претерпели изменения, которые связывают с развитием виноделия и употреблением ягод в свежем виде. В процессе одомашнивания земледельцы учитывали содержание сахаров в ягодах и отбирали генотипы с более крупными, привлекательными, сладкими ягодами, это же приводило и к отбору гермафродитных форм, упрощавших возделывание культуры. В настоящее время обоеполый тип цветка - это основной признак, который отличает дикий виноград от культурного (Zecca et al., 2010).

Современный культурный виноград считается относительно недавним потомком дикорастущих форм, благодаря чему он должен сохранять многие генетические особенности, свойственные популяциям предков. Сравнение генотипов современных сортов с генотипами из дикорастущих популяций может показать, какие именно дикорастущие популяции являлись в прошлом объектом доместикации (Brown et al., 2009). Дикие родичи видов сельскохозяйственных культур имеют большое значение для селекционеров в качестве уникальных источников генетической изменчивости для использования в селекционных целях.

\section{Доместикация винограда}

Дикорастущий виноград был распространен в Южной Европе, а также в Западной Центральной Азии начиная с эпохи неолита. Согласно археологическим данным, первое введение в культуру винограда произошло на Ближнем Востоке (McGovern et al., 1996). Также одним из основных мест ранней доместикации винограда и зарождения виноделия считается территория Южного Кавказа (Азербайджан, Армения, Грузия) и восточные регионы Турции (Levadoux, 1956; Zohary, 1995; This et al., 2006). Вместе с тем некоторые исследования свидетельствуют о том, что имели место и вторичные события доместикации винограда в Средиземноморьe (Aradhya et al., 2003; Grassi et al., 2003; Arroyo-García et al., 2006; Lopes et al., 2009; De Andrés et al., 2012).

На сегодняшний день, дикорастущие популяции винограда считаются, по большей части, смесью диких и культурных форм, а также спонтанных гибридов между ними (Lacombe et al., 2003; Laguna, 2003; This et al., 2006). Исследование генома винограда могло бы прояснить многие вопросы, связанные с эволюцией видов Vitis и их внутривидовым генетическом разнообразием. Так, например, был проведен анализ хлоропластного генома винограда; установлено, что его размер равен 160928 п.н., а порядок и структура генов идентичны таковым во многих других растительных геномах (Arroyo-García et al., 2002). Однако внутривидовой полиморфизм хлоропластного генома был исследован без применения технологий высокопроизводительного секвенирования, лишь с помощью микросателлитных маркеров, которые выявляли полиморфизм 34 различных локусов. В результате как для V. vinifera ssp. sativa, так и для V. vinifera ssp. sylvestris были идентифицированы хлоротипы (хлоропластные гаплотипы), специфичные для конкретных географических регионов. Приуроченность различных типов хпДНК к определенным регионам также может прояснить вопрос о количестве событий доместикации (Gracía, 2013).

\section{Состояние вопроса о полногеномном секвенировании культурного и дикорастущего винограда}

Современные методы секвенирования можно разделить на три поколения: секвенирование методом терминации цепи (метод Сэнгера), секвенирование синтезом (Illumina) и секвенирование единичных молекул в реальном времени (SMRT, ONT). Метод терминации цепи был предложен в 1970-х гг. (Sanger et al., 1977) и усовершенствован в 1985 г. путем замены радиоактивной метки на нуклеотиды, конъюгированные с флуорохромами (Smith et al., 1986). Этот метод является экономически выгодным, хотя имеет ограничения в производительности: за один запуск в одном капилляре читается один фрагмент цепи ДНК при максимальной длине прочтения до 900 п.н.

Второе поколение секвенирования (Next Generation Sequencing, NGS), помимо повсеместно используемого секвенирования путем синтеза цепи, также включает в себя метод пиросеквенирования. Последний был впервые предложен в 1988 г. (Hyman, 1988), в его основе лежит механизм высвобождающегося пирофосфата при присоединении полимеразой нуклеотида, связывающегося с люциферазой, с последующей детекцией светового сигнала. Секвенаторы, основанные на такой технологии, имеют несколько большую производительность, однако не позволяют с высокой точностью определять нуклеотидный состав гомополимерных участков. Такой метод хорошо подходит для быстрого секвенирования коротких последовательностей ДНК и РНК, для выявления мутаций, что снижает время и стоимость исследования в сравнении с капиллярным электрофорезом (Montero et al., 2008). На данный момент полногеномное секвенирование по Сэнгеру и пиросеквенирование потеряли свою актуальность и уступили место более современным и дешевым методам, таким как секвенирование синтезом на Illumina. Секвенаторы данной технологии используют секвенирование на молекулярных кластерах с использованием флуоресцентно меченных предшественников, в своих последних вариантах позволяют получить до 6000 млрд нуклеотидов и до 20 млрд прочтений выходных данных, что существенно ускоряет работы по полногеномному секвенированию. Например, с использованием технологии Illumina был секвенирован геном Picea abies (L.) H. Karst., размер которого, по результатам сборки, оценивается в 19.6 млрд нуклеотидов (Nystedt et al., 2013).

Стоит отметить, что первая полногеномная сборка винограда была осуществлена с использованием метода секвенирования по Сэнгеру с дополнением методом пиросеквенирования (454 Life Science). Библиотеки для секвенирования были подготовлены по методу дробовика (whole genome sequencing, WGS). При использовании этого метода ДНК фрагментируют на мелкие участки (100-300 нуклеотидов) случайным образом, а затем секвенируют любым из методов.

\section{Результаты полногеномного секвенирования культурных и дикорастущих форм винограда} Современные методы селекции экономически важных культур предполагают наличие информации об их геноме. Известно, что большинство признаков имеют полигенный характер, то есть 
Таблица 1. Общая статистика геномной сборки V. vinifera (по результатам Jaillon et al., 2007)

Table 1. General characterization of whole genome assembly of $V$. vinifera (according to the results of Jaillon et al., 2007)

\begin{tabular}{|c|c|c|c|c|c|c|}
\hline Статус сборки & Статус & Количество & NM, Kб & Длина, Кб & Размер, мб & $\begin{array}{l}\text { Процент } \\
\text { в сборке }\end{array}$ \\
\hline Контиги & Все полученные & 19577 & 65.9 & 557 & 467.5 & - \\
\hline Суперконтиги & $\begin{array}{l}\text { Привязанные } \\
\text { к хромосомам }\end{array}$ & 191 & 3189 & 12675 & 335.6 & 68.9 \\
\hline Аннотация & Количество & Средний размер, п.н. & $\begin{array}{l}\text { Общая длина, } \\
\text { Мб }\end{array}$ & $\begin{array}{l}\text { Проценты } \\
\text { генома }\end{array}$ & $\% G C$ & \\
\hline Генов & 30434 & 3399 & 225.6 & 46.3 & 362 & \\
\hline Межгенные регионы & 30453 & 3544 & 2615 & 34.7 & 33.0 & \\
\hline TPHK* & 600 & 73 & 0.04 & NS & 43.0 & \\
\hline микроРНК ${ }^{* *}$ & 164 & 1035 & 0.002 & NS & 35.9 & \\
\hline Ортология & $\begin{array}{l}\text { Количество } \\
\text { ортологичных белков }\end{array}$ & $\begin{array}{l}\text { Средняя } \\
\text { идентичность, \% }\end{array}$ & & & & \\
\hline P. trichocarpa & 12996 & 72.7 & & & & \\
\hline A. thaliana & 11404 & 65.5 & & & & \\
\hline O. sativa & 9731 & 59.8 & & & & \\
\hline
\end{tabular}

* значения рассчитаны для экзонов

** консервативные семейства микроРНК

*** эвдикоты представлены P. trichocarpa и A. thaliana

**** магнолифиты представлены P. trichocarpa, A. thaliana и O. sativa

контролируются комплексом генов. В таком случае информация о геноме должна быть доступна в виде полногеномной последовательности (Reference sequence). С целью секвенирования культурного винограда был создан интернациональный консорциум (Grape Genome Program, https://www6.inra.fr/iggp, в результате работы которого была опубликована полногеномная последовательность культурного винограда. Она стала первым опытом полногеномной сборки для плодовых культур. В качестве объекта секвенирования была выведена линия винограда, полученная путем нескольких раундов последовательного самоопыления сорта Пино Нуар (PN4002), в результате чего гомозиготность этой линии составила около $93 \%$. Необходимость создания такой линии была обусловлена тем, что обычно сорта винограда показывают достаточно высокий уровень гетерозиготности (до $13 \%$ ), что препятствовало бы надежному формированию контигов в процессе сборки. Секвенирование было выполнено по методу Сэнгера с помощью технологии WGS. В результате было получено 8.4-крат- ное покрытие генома: 6.2 млн парно-концевых прочтений (Jaillon et al., 2007; табл. 1).

Текущая версия сборки линии PN40024 (GCA_000003745.2), депонированная в базу данных NCBI 2009/12/17, имеет 12-кратное покрытие, которое было получено путем комбинирования технологий секвенирования методом Сэнгера и пиросеквенирования на платформе 454 Life Science. Финиширование сборки и сборка мета-контигов были произведены с помощью добавления двух ВАС-библиотек (http://bioinformatics.psb.ugent.be/genomes/view/ Vitis-vinifera).

По результатам сборки было получено 59883 контига, собранных в 2093 мета-контига, упорядоченных по 19 хромосомам. Упорядочивание по хромосомам производили с помощью генетической карты, полученной для скрещивания F1 сортов Syrah $\times$ Pinot Noir и генотипированной с использованием 1006 маркеров (Troggio et al., 2007). Для улучшения упорядочивания в анализ были также включены данные об однонуклеотидных полиморфизмах 
Таблица 2. Количество и размеры собранных последовательностей (по Velasco et al., 2007)

Table 2. Amount and size of assembled reads (according to the results of Velasco et al., 2007)

\begin{tabular}{|c|c|c|c|}
\hline Показатель & Количество & Общая длина, Мб & Вклад в размер генома, Мб \\
\hline Полиморфные контиги & 36550 & 465.7 & \\
\hline Пропуски в гетерозиготах & & 48.9 & 24.5 \\
\hline Последовательности без пропусков & & 416.8 & 416.8 \\
\hline Неполиморфные контиги & 22061 & 65.1 & 32.5 \\
\hline Центромерные регионы & & 14.5 & 14.5 \\
\hline Кластеры рРНК & & 16.3 & 16.3 \\
\hline Всего & 58611 & & 504.6 \\
\hline
\end{tabular}

\section{Admixture proportions}
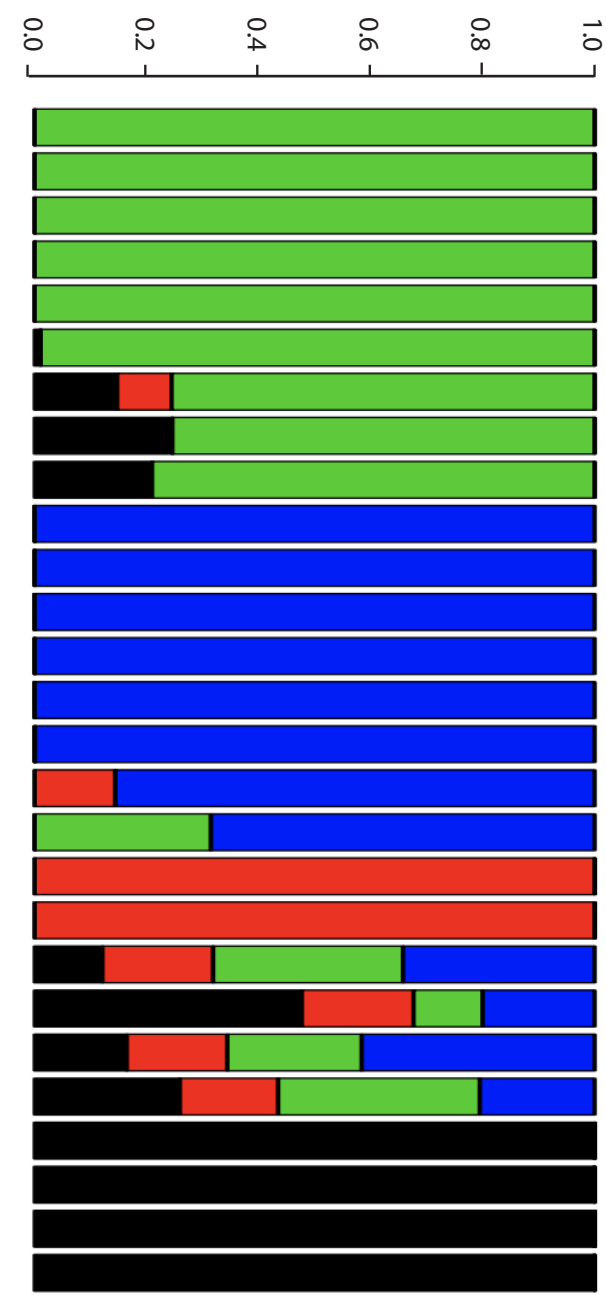

$\left.\begin{array}{l}\text { Azerbaijan1 } \\ \text { Azerbaijan2 } \\ \text { Georgia } \\ \text { Armenia } \\ \text { Turkmenistan1 } \\ \text { Turkmenistan2 } \\ \text { Pakistan1 } \\ \text { Pakistan2 } \\ \text { Pakistan3 } \\ \text { Aramon } \\ \text { Chardonnay } \\ \text { Pinot_Noir_123 } \\ \text { Semillion_12 } \\ \text { Traminer_1 } \\ \text { Gamay_Noir3 } \\ \text { Riesling_4 } \\ \text { Cabernet_Sauvignon08 } \\ \text { Primitivo03 } \\ \text { Zinfandel_03 } \\ \text { Muscat_of_Alexandria } \\ \text { Autumn_Royal } \\ \text { Italia } \\ \text { Red_Globe } \\ \text { Sultanina } \\ \text { Thompson_2A } \\ \text { Thompson_RLK } \\ \text { Thompson_Seedless }\end{array}\right\}$

Популяционная структура образцов V. vinifera ssp. sylvestris и V. vinifera ssp. vinifera по результатам Zhou et al., 2017 (проект № PRJNA388292).

Population structure of $V$. vinifera ssp. sylvestris and $V$. vinifera ssp. vinifera samples according to the results of Zhou et al., 2017 (project No. PRJNA388292). 
(SNP), полученные во время секвенирования методом WGS по Сэнгеру, с использованием системы генотипирования SNPlex. Максимальное генетическое расстояние между маркерами на группах сцепления не превышало 35 сM с минимальным значением LOD $=0.8$ (Velasco et al., 2007).

Для выявления гомологичных и видоспецифичных последовательностей ДНК в полученной сборке был использован алгоритм поиска гомологий BLAST (https://blast.ncbi.nlm.nih.gov/Blast.cgi). Поиск гомологичных участков генома винограда осуществлялся с такими видами, как рис, тополь и арабидопсис. Это помогло идентифицировать не только ортологичные гены, но и паралоги в геноме винограда.

По результатам анализа для винограда было предсказано 29585 генов, из которых 96.1 \% находились в идентифицированных группах сцепления.

Из-за высокой гетерозиготности V. vinifera при сборке было выявлено множество гаплотип-специфических пробелов (последовательности, присутствующие в одном гаплотипе, но отсутствующие в другом). Общая длина таких пробелов составила 48.9 Мб. Причина этого в том, что в некоторых областях варианты гаплотипов были настолько различны вследствие гетерозиготности, что алгоритм не мог объединить их в один контиг. Множество таких необъединенных контигов сформировало гемизиготную ДНК (22 061 контиг длиной 65.1 Мб).

Общий размер генома оценивали как сумму гомологичных последовательностей для всех гаплотипов, объединенных в единый консенсус (416 × 2 = 836 Мб), и длину последовательности, представленной гемизиготной ДНК и пропусками. Таким образом, с включением длины последовательностей центромерных областей $(14.5 \times 2+16.3 \times 2=61.6$ Мб $)$ размер диплоидного генома винограда составил 1009. 2 Мб, что в среднем составляет 504.6 Мб для гаплоидного генома (табл. 2). Эти результаты сопоставимы с информацией о геноме винограда, полученной ранее при создании генетической карты (Lodhi et al., 1995).

Наряду с этой сборкой, в NCBI сегодня депонированы также «черновые» варианты сборки таких сортов, как Месхетинский зеленый, Чхавери, Саперави, Ркацители, Шардоне. Однако для этих сборок не была реализована стадия финиширования, то есть закрытия пропусков между скаффолдами с последующей привязкой к хромосомам. Поэтому уровень сборки для грузинских сортов оценивается как «сборка по скаффолдам». Геном сорта Шардоне был собран на уровне «сборка для контигов».

Полногеномное секвенирование сортов Месхетинский зеленый, Чхавери, Саперави, Ркацители было инициировано Университетом сельского хозяйства Грузии (Agricultural University of Georgia). В рамках этого проекта была секвенирована как ядерная, так и внеядерная (хлоропластная и митохондриальная) ДНК. Выбор сортов был сделан таким образом, чтобы каждый из сортов представлял собой отдельную пластидную гаплогруппу: Чхавери (GTA), Саперави (ATT), Месхетинский зеленый (ATA), Ркацители (AAA) (Beridze et al., 2011; Tabidze et al., 2014).

Кроме того, с целью изучения вопросов доместикации, по методу WGS (Illumina) были секвенированы образцы дикорастущего винограда с различным географическим происхождением: Азербайджан (2 образца), Грузия (1 образец), Армения (1 образец), Туркменистан (2 образца), Пакистан (3 образца) - в сравнении с 11 сортами культурного винограда (рисунок). Анализ структуры популяций дикорастущего и культурного винограда показал, что образцы V. vinifera ssp. sylvestris формируют отдельную группу в пространстве главных компонент; сорта столового и винного винограда также относились к разным кластерам. В результате проведенного анализа SNP установлено, что предполагаемое расхождение между видами культурного и дикого винограда произошло примерно 22 тыс. лет назад (Zhou et al., 2017).

С целью изучения формирования цветков у диких видов было произведено секвенирование транскриптома по методу RNA-seq. Для этого были получены профили мРНК цветков дикорастущих форм на четырех стадиях развития цветка, и те же стадии были проанализированы для цветков культурного вида с женских и мужских растений (проект № SRR1239522) (Ramos et al., 2014).

\section{Заключение}

В настоящее время в базах данных нуклеотидных последовательностей доступна информация о полногеномном секвенировании культурных видов винограда и их дикорастущих предков. В базе данных $\mathrm{NCBI}$ депонирована полногеномная сборка линии культурного винограда PN40024 (GCA_000003745.2), а также данные о секвенировании широко используемых в виноделии сортов Месхетинский зеленый, Чхавери, Саперави, Ркацители. В базе данных ENA доступны необработанные данные секвенирования 9 дикорастущих видов винограда и 11 культурных форм с целью изучения вопроса доместикации. Также доступны данные о секвенировании мРНK V. vinifera ssp. sylvestris, представляющих интерес для исследований генетики пола у винограда.

В базах данных отсутствует информация о полногеномной сборке дикорастущего винограда. Однако уже опубликованные результаты открывают возможность более глубоко взглянуть на историю культуры винограда, процессов его доместикации и сделать шаг от селекции винограда классическими методами к маркер-вспомогательной селекции.

\section{Список литературы / References}

Бузин Н., Принц Я., Лазаревский М., Негруль А., Кац Я. Виноградарство. М.; Л.: Сельхозгиз, 1937.

[Buzin N., Prince Y., Lazarevsky M., Negrul A., Katz Y., Viticulture. M.; L.: Agricultural publishing house, 1937. (in Russian)]

Волынкин В.А., Полулях А.А. Эволюционное формирование генетического разнообразия культурных сортов и диких родичей у винограда. Труды по прикладной ботанике, генетике и селекции. 2009;166:364-372.

[Volynkin V.A., Polulyah A.A. Evolutionary formation of genetic diversity of cultivars and wild relatives at the grapevine. Trudy po Prikladnoy Botanike, Genetike $i$ Selektsii = Proceedings on Applied Botany, Genetics and Breeding. 2009;166:364-372. (in Russian)]

Негруль А.М. Виноградарство и виноделие. Рипол Классик, 1968.

[Negrul A.M. Viticulture and winemaking. Ripol Classic. 1968. (in Russian)]

Aradhya M.K., Dangl G.S., Prins B.H., Boursiquot J.M., Walker M.A., Meredith C.P., Simon C.J. Genetic structure and differentiation in cultivated grape, Vitis vinifera L. Genet. Res. 2003;81(3)179-192.

Arnold C., Schnitzler A., Parisot C., Maurin A. Historical reconstruction of a relictual population of wild grapevines (Vitis vinifera ssp. sylvestris, Gmelin, Hegi) in a floodplain forest of the upper Seine valley, France. River Res. Appl. 2010;26(7):904-914.

Arroyo-García R., Lefort F., Andrés M.T.D., Ibáñez J., Borrego J., Jouve N., Cabello F., Martínez-Zapater J.M. Chloroplast microsatellite polymorphisms in Vitis species. Genome. 2002;45(6):1142-1149.

Arroyo-García R., Ruiz-Garcia L., Bolling L., Ocete R., Lopez M.A., Arnold C., Ergul A., Söylemezo Lu G., Uzun H.I., Cabello F., Ibanez J. Multiple origins of cultivated grapevine (Vitis vinifera L. ssp. sativa) based on chloroplast DNA polymorphisms. Mol. Ecol. 2006;15(12):3707-3714. 
Beridze T., Pipia I., Beck J., Hsu S.C., Gamkrelidze M., Gogniashvili M., Tabidze V., This P., Bacilieri R., Gotsiridze V., Glonti M. Plastid DNA sequence diversity in a worldwide set of grapevine cultivars (Vitis vinifera L. ssp. vinifera). Bull. Georgian Nat. Acad. Sci. 2011;5:91-96.

Bioinformatics and Evolutionary Genomics; 2007 [обновлено 2015; процитировано 10 сентября 2019]. Доступно: http://bioinformatics.psb. ugent.be/genomes/view/Vitis-vinifera

Blast Local Alignment Search Tool [сайт]. NCBI National Center for Biotechnology Information; 1990[обновлено 27 сентября 2019; процитировано 29 сентября 2019]. Доступно: https://blast.ncbi.nlm.nih.gov/Blast. cgi.

Brown T.A., Jones M.K., Powell W., Allaby R.G. The complex origins of domesticated crops in the Fertile Crescent. Trends Ecol. Evol. 2009;24(2):103109.

De Andrés M.T., Benito A., Pérez-Rivera G., Ocete R., Lopez M.A., Gaforio L., Muñoz G., Cabello F., Martínez Zapater J.M., Arroyo-García R. Genetic diversity of wild grapevine populations in Spain and their genetic relationships with cultivated grapevines. Mol. Ecol. 2012;21(4):800-816.

García R.A.A., Revilla E. The current status of wild grapevine populations (Vitis vinifera ssp. sylvestris) in the Mediterranean basin. InTech. 2013; 51-72.

Grassi F., Labra M., Imazio S., Spada A., Sgorbati S., Scienza A., Sala F. Evidence of a secondary grapevine domestication centre detected by SSR analysis. Theor. Appl. Genet. 2003;107(7):1315-1320.

Grape Genome Program. INRA; 2017 [обновлено 3 июля 2018; процитировано 10 сентября 2019]. Доступно: https://www6.inra.fr/iggp

Hyman E.D. A new method of sequencing DNA. Anal. Biochem. 1988;174(2):423436.

Jaillon O., Aury J.M., Noel B., Policriti A., Clepet C., Casagrande A., Choisne N., Aubourg S., Vitulo N., Jubin C., Vezzi A. The grapevine genome sequence suggests ancestral hexaploidization in major angiosperm phyla. Nature. 2007;449(7161):463.

Lacombe T., Laucou V., Di Vecchi M., Bordenave L., Bourse T., Siret R., David J., Boursiquot J.M., Bronner A., Merdinoglu D., This P. Inventory and characterization of Vitis vinifera ssp. sylvestris in France. Acta Horticulturae, 2003.

Laguna Lumbreras E. Sobre las formas naturalizadas de "Vitis vinifera L." en la Comunidad Valenciana, I. Especies. Flora Montiberica. 2003;(23):46-82. (in Spanish)

Levadoux L. Les populations sauvages et cultivées des Vitis vinifera L. Institut national de la recherche agronomique. 1956;1. (in French)

Lodhi M.A., Ye G.N., Weeden N.F., Reisch B.I., Daly M.J. A molecular marker based linkage map of Vitis. Genome. 1995;38(4):786-794.

Lopes M.S., Mendonça D., Rodrigues dos Santos M., Eiras-Dias J.E., da Câmara Machado A. New insights on the genetic basis of Portuguese grapevine and on grapevine domestication. Genome. 2009;52(9):790-800.
McGovern P.E., Glusker D.L., Exner L.J., Voigt M.M. Neolithic resinated wine. Nature. 1996;381(6582):480.

Montero C.I., Shea Y.R., Jones P.A., Harrington S.M., Tooke N.E, Witebsky F.G., Murray P.R. Evaluation of pyrosequencing technology for the identification of clinically relevant non dematiaceous yeasts and related species. Eur. J. Clin. Microbiol. Infect. Dis. 2008;27(9):821-830.

Nystedt B., Street N.R., Wetterbom A., Zuccolo A., Lin Y.C., Scofield D.G., Vezzi F., Delhomme N., Giacomello S., Alexeyenko A., Vicedomini R. The Norway spruce genome sequence and conifer genome evolution. Nature. 2013;497(7451):579.

Ocete R., López M.Á., Gallardo A., Arnold C. Comparative analysis of wild and cultivated grapevine (Vitis vinifera) in the Basque Region of Spain and France. Agric. Ecosys. Envir. 2008;123(1-3):95-98.

Sanger F., Nicklen S., Coulson A.R. DNA sequencing with chain-terminating inhibitors. Proc. Nati. Acad. Sci. USA. 1977;74(12):5463-7.

Smith L.M., Sanders J.Z., Kaiser R.J., Hughes P., Dodd C., Connell C.R., Heiner C., Kent S.B., Hood L.E. Fluorescence detection in automated DNA sequence analysis. Nature. 1986;321(6071):674-679.

Tabidze V., Baramidze G., Pipia I., Gogniashvili M., Ujmajuridze L., Beridze T., Hernandez A.G., Schaal B. The complete chloroplast DNA sequence of eleven grape cultivars. Simultaneous resequencing methodology. OENO One. 2014:48(2):99-109.

This P., Lacombe T., Thomas M.R. Historical origins and genetic diversity of wine grapes. TRENDS in Genet. 2006;22(9):511-519.

Troggio M., Malacarne G., Coppola G., Segala C., Cartwright D.A., Pindo M., Stefanini M., Mank R., Moroldo M., Morgante M., Grando M.S. A dense singlenucleotide polymorphism-based genetic linkage map of grapevine (Vitis vinifera L.) anchoring Pinot Noir bacterial artificial chromosome contigs. Genet. 2007;176(4):2637-2650.

Ramos M.J.N., Coito J.L., Silva H.G., Cunha J., Costa M.M.R., Rocheta M. Flower development and sex specification in wild grapevine. BMC Gen. 2014;15(1):1095.

Velasco R., Zharkikh A., Troggio M., Cartwright D.A., Cestaro A., Pruss D., Pindo M., FitzGerald L.M., Vezzulli S., Reid J., Malacarne G. A high quality draft consensus sequence of the genome of a heterozygous grapevine variety. PloS One. 2007;2(12):e1326.5.

Zecca G.A., De Mattia F., Lovicu G., Labra M., Sala F., Grassi F. Wild grapevine: silvestris, hybrids or cultivars that escaped from vineyards? Molecular evidence in Sardinia. Plant Biol. 2010;12(3):558-562.

Zhou Y., Massonnet M., Sanjak J.S., Cantu D., Gaut B.S. Evolutionary genomics of grape (Vitis vinifera ssp. vinifera) domestication. Proc Nat. Acad. Sci. 2017;114(44):11715-11720.

Zohary D. The domestication of the grapevine Vitis vinifera L. in the Near East. Origins Ancient History Wine. Routledge. 2003;44-51.

Конфликт интересов. Авторы заявляют об отсутствии конфликта интересов.

Для цитирования. Григорьева Е.А., Агаханов М.М., Александрова И.В., Волков В.А. Полногеномное секвенирование культурных и дикорастущих форм винограда (Vitis vinifera L.). Письма в Вавиловский журнал генетики и селекции. 2019;5(1):13-18. DOI 10.18699/Letters2019-5-2.

For citation. Grigoreva E.A., Agakhanov M.M., Alexandrova I.V., Volkov V.A. Whole genome sequencing of cultivated and wild varieties of grapevine (Vitis vinifera L.). Pisma v Vavilovskii Zhurnal Genetiki i Selektsii = Letters to Vavilov Journal of Genetics and Breeding. 2019;5(1):13-18. DOI 10.18699/Letters2019-5-2. (in Russian)

Поступила в редакцию 15.10.2019. После доработки 29.10.2019. Принята к публикации 29.10.2019. 